\title{
Experiences of Children's Care Received at Windhoek Residential Child Care Facilities, Namibia
}

\author{
Brigitte Nshimyimana*, Marieta Van der Vyver, Joan M. Kloppers \\ School of Nursing and Public Health, Faculty of Health Science, University of Namibia, Windhoek, Namibia \\ Email: ${ }^{*}$ briguza@yahoo.com
}

Received 24 July 2015; accepted 15 September 2015; published 18 September 2015

Copyright (C) 2015 by authors and Scientific Research Publishing Inc.

This work is licensed under the Creative Commons Attribution International License (CC BY). http://creativecommons.org/licenses/by/4.0/ (c) (7) Open Access

\section{Abstract}

The caring is a very important aspect for every child's well-being and development. A child should be cared for by biological parents or extended family members when possible. In the absence of these two possibilities, other options are in place such as Residential Child Care Facilities (RCCFs). However, RCCFs are generally regarded as last resorts, as it is noted that they have a negative impact on the well-being of the children. Caregivers in RCCFs should ensure that these children are being adequately cared for as they substitute their biological or extended families. It is also a child's rights to be provided love, care and support coupled with a sense of belonging, recognition and independence. However, children without or inadequate parental care are likely to be vulnerable from all forms of violence. The aim of this qualitative, exploratory, descriptive, contextual and phenomenological study was to explore and describe the children's experiences regarding the care received at the Residential Child Care Facilities and to provide recommendations regarding research findings. Data were collected through one on one in-depth interviews and Tech method was used to analyze data. The results of the study show that children in RCCFs have experienced both positive and negative care. The care is experienced through relationships with staff in the facilities, provision of their basic needs, knowledge of their cultural identity and their adult future preparation once they leave the facilities. Thus, it is recommended that a conducive environment that contributes to the quality of care for children in RCCFs be established, taking into consideration human resources capacity, policy guidelines and standards in place while providing care to those children.

\section{Keywords}

Experiences, Children, Care, Residential, Facilities

\footnotetext{
${ }^{*}$ Corresponding author.

How to cite this paper: Nshimyimana, B., Van der Vyver, M. and Kloppers, J.M. (2015) Experiences of Children's Care Received at Windhoek Residential Child Care Facilities, Namibia. Open Journal of Nursing, 5, 773-783.

http://dx.doi.org/10.4236/ojn.2015.59081
} 


\section{Introduction}

It is the fundamental right of a child to grow up in a safe, nurturing, consistent care-giving environment, free from maltreatment such as physical, sexual, and emotional abuse, neglect, as well as inadequate physical care [1]. However, children deprived of parental care are vulnerable to abuse, exploitation and further maltreatment [2]. In such situations, the immediate intervention is to find ways to entrust the care of these children with extended families. But for those children who do not have any family members to take care of them, there are other long or short-term options available such as Residential Child Care Facilities (RCCFs).

Residential Child Care Facilities are defined as "a group living arrangement for more than ten (10) children, without parents or surrogate parents, in which care is provided by a much smaller number of paid adult careers" [3]. Residential Child Care Facilities have a mandate to help children without parents or proper parental care, to grow up in a family set-up environment.

It is estimated that Namibia has 250,000 orphans and vulnerable children (OVC) of which 155,000 children have lost one or both parents [4]. The Government of the Republic of Namibia encourages that such children should be placed in the care of extended families and communities. However, extended families and communities do not always have the willingness and capacity to do so. There is a need for appropriate alternative quality care for those children. Such children are consequently placed in RCCFs, although RCCFs are regarded as the last resort. Due to the absence of appropriate parental care, the country is experiencing a rapidly growing number of RCCFs. The Government of Namibia has developed and put in place a Minimum Standards of Caring in Namibia. However, some of those facilities were established without consulting legislation framework, policies, guidelines and standards. As a result, children experience additional neglect, abuse or exploitation by over-burdened or uncaring "care providers" [5].

There is a significant number of children residing in RCCFs in Namibia due to different difficult circumstances faced by their biological parents and their extended families. Hence, scores of children are left alone without proper parental care and the extended family members are unable to cope with this growing number of OVC in need of care and protection. As the last resort, these children are placed in RCCFs. In order to regulate RCCFs and ensure quality care of children, the Ministry of Gender Equality and Child Welfare, Namibia has developed legislations, policies, guidelines and standards developed. Thus, it is important to know the experiences of children and the nature of the quality of care being provided to them in such facilities. Such experiences and knowledge are not widely documented in Namibia and information of this nature is unavailable. It is for this reason that the researcher wished to explore and describe the children's experiences regarding the care received at the RCCFs, focusing on facilities in Windhoek.

The overall purpose of the study was to explore and describe the children's experiences regarding the care received at the RCCFs in Windhoek and to provide recommendations based on research findings. The objectives of the study were to carry out a situational analysis in order to explore and describe the children's experiences regarding the care received at the Windhoek RCCFs and provide recommendations to the Ministry of Gender Equality and Child Welfare based on the research findings.

\section{Methods}

For the purpose of this study a qualitative, explorative, descriptive and contextual design was used throughout the research process. Researchers who desire "to explore the meaning, describe and promote understanding of human experiences such as pain, grief, hope or caring, or unfamiliar phenomena use qualitative research” [6]. The research method used in this study was one-on one in depth interviews; this method is mostly associated with words, language and experiences instead of measurements, statistics and numerical data. In addition, the phenomenological approach was used and allowed the participants, through in-depth interviews, to deduce the meaning of their experiences in the specific context settings of the RCCFs.

\subsection{Sampling and Sample Size}

A purposive sampling method was used and the inclusion criteria were considered for the two different populations. i.e. RCCFs and children. Children respondents were aged between 15 - 18, able to communicate in English, willing to participate and able to contribute meaningfully to the study. The size of the sample was determined by the saturation of data during the data collection process. Thus, a number of twenty two participants (22) were interviewed. The Managers of registered RCCFs in Windhoek identified eligible children to be interviewed. 
The tree facilities were selected based on the fact that there was only one government owned facility and the rest were private and church-owned RCCFs. Therefore, one government, one private and one church owned RCCFs were considered and they were willing to accommodate the researcher's activities.

\subsection{Data Collection}

The researcher visited the facilities identified for the study ahead of data collection to present herself, request for permission to conduct interviews, as well as to seek consent from purposively selected children to participate in the study. Reference [7] asserts that spoken or written language is used to generate qualitative data. Therefore, One on one in-depth interviews were conducted at the three RCCFs based in Windhoek by researcher. Detailed information about the research project and the right of individuals to informed consent was explained to ensure that the interviews were understood and that participation was voluntary and confidential.

Interviews took place during the month of August 2013 and children were available in the afternoon after school. All interviews lasted between 30 - 45 minutes and were held in each specific facility boardroom. The data collection process included the preparation of the field and conducting of interviews with the participants while taking field notes by the researcher who is the first author of this paper. The following central question was posed in order to collect data: "How do you experience the care that you receive in this home?"

During data collection, communication skills with in in-depth interviews were applied including active listening, paraphrasing, reflecting, probing and clarification. The researcher was an experienced Social Worker and had experience and skills of interviewing children and an understanding of the subject matter.

\subsection{Data Analysis}

The Tesch's [8] method of open coding was used for the analysis of data. The transcription, coding of interviews and analysis were done by the researcher. Data from spoken words was obtained through one-on-one in-depth interviews which were tape recorded and augmented by field notes. Verbal responses were transcribed, typed into the computer using Microsoft Office Word. Notes and tape recordings were compared to ensure consistency and accuracy. Furthermore, by repeatedly listening to the recordings and reading the notes, the researcher became familiar with the contents of the interviews.

The researcher worked on a soft copy whereby words and phrases that were used to give meaning to certain feelings and behaviour and/or concepts were recorded. The inductive approach was used because qualitative research was a major design of the inquiry [9], and emergent the framework was used to group information. After that the relationships between the data collected were considered.

The content of the message, attitude of the interviewees towards the question and the degree to which the participants represented their experiences in terms of the topic were contemplated. Information was colour coded and categorized in themes and sub-themes were converted and clustered into concepts.

\subsection{Ethical Considerations}

The researcher has conformed to ethical measures before and after the process of interviewing children. Since the research topic was sensitive, intimate and innermost matters in children's concerned lives [10]. Thus, further measures of respect for persons, beneficence, justice, and permission, sensitivity of specific needs, participation and protection were respected:

\subsubsection{Permission}

The research proposal was submitted to the University of Namibia's Postgraduate Studies Committee and approval was granted to conduct the study. Permission was sought and given by the Ministry of Gender Equality and Child Welfare to conduct the study. Additional permission was acquired from the managers of the participating facilities as well as written consent for children and their specific housemothers.

\subsubsection{Measures of Respect for Persons}

Individuals are autonomous which means that "they have the right to self-determination" [6] and they are able to control their own lives. In this case participants were children who were not able to control their lives without the support of their caregivers. Therefore, participation was voluntary and informed consent was requested from 
the participants and additional informed consent soughed from the management of the RCCFs and their caregivers.

\subsubsection{Measure of Beneficence}

The researcher secured the well-being of the participants through protecting them from discomfort and harm [6]. The researcher made sure that the participants were monitored throughout the process of interviews. However, there was no sign of discomfort to any participant. Thus, no participant was withdrawn from the interview process.

\subsubsection{Measure of Justice}

Participants have the right to fair selection and treatment [6]. The researcher selected participants for the study according to criteria of participants outlined in the research methodology. Privacy, anonymity and confidentiality were assured. It was agreed with the participants that the conversation during the interviews was not to be shared with other children or caregivers. Further measures of privacy and anonymity were put in place such as discarding of the tape recordings when validation and data analysis were completed.

\subsubsection{Sensitivity to Specific Needs}

This provision means that the researcher should not unjustly single out or overburden any group of children for increased exposure to risk on the basis of their particular medical condition, disability, ethnic or social circumstances [11]. This ethical measure was adhered to by minimizing distress and disruption for unwanted intrusion into their privacy by getting a private room, far from where other children and staff members were. No child was excluded because of their physical disability, ethnicity or social circumstances, except if he/she was not able to speak English or not in the range of 15 - 18 years. The researcher was also sensitive to the diversity and individuality of children, and was non-judgmental with regard to children's care experience and family circumstances.

\subsubsection{Participation and Protection}

A researcher who is dealing with child participants should have adequate knowledge and acceptable attitude in relation to children with specific needs. Therefore, the researcher should be aware of issues that might arise in studying children in a specific context [11]. The researcher adhered to this measure by applying her experience as a social worker, as well as her extensive understanding and skills in field of child welfare services including protection and their legal rights.

\section{Results and Discussion}

The results of the study were presented and discussed in terms of the final categories identified as themes and sub-themes (see Table 1) on experiences of children regarding their care in Windhoek Residential Child Care Facilities (RCCFs). Interviews were conducted until the data was saturated.

\subsection{Theme 1: Participants Experienced Positive and Negative Dimensions in Their Relationships with Their Housemothers and Other Staff Members in the Facilities}

The participants felt that their relationship with their caregivers and other staff members in the facility was one of the most important aspects contributing to the experience of the care they have received. Reference [12] revealed that children in residential care often identify positive relationships with staff members, as essential to their experiences of care. Good quality attachments and nurturing care experiences are important factors for children to be able to form significant relationships [13].

\subsubsection{Sub-Theme: Positive Relationship}

Features contributing to positive relationship in terms of the care received by participants were thought to be mutual respect and good communication, love, support and care, as well as participation in everyday life decisions.

\section{Mutual respect and good communication}

Some children felt that mutual respect and good communication had contributed to the care they had received 
Table 1. Identified themes and sub-themes on experiences of children regarding their care

\begin{tabular}{|c|c|}
\hline Themes & Sub-themes \\
\hline $\begin{array}{l}\text { Theme 1: } \\
\text { Participants experienced positive and negative dimensions in their relationships } \\
\text { with their housemothers and other staff members in the facilities. }\end{array}$ & $\begin{array}{l}\text { Positive relationship } \\
\text { - } \quad \text { Mutual respect and good communication. } \\
\text { - } \quad \text { Love, support and care. } \\
\text { - } \quad \text { Participation in everyday life decisions. } \\
\text { Negative relationship } \\
\text { - } \quad \text { Being uncomfortable. } \\
\text { - } \quad \text { Loneliness and sadness. }\end{array}$ \\
\hline $\begin{array}{l}\text { Theme 2: } \\
\text { Children experienced provision of their basic needs as an important factor in the } \\
\text { caring dimension. }\end{array}$ & $\begin{array}{l}\text { Provision of basic needs } \\
\text { - } \quad \text { Education needs. } \\
\text { - } \quad \text { Material needs (Food, clothing and shelter). } \\
\text { - } \quad \text { Health needs. } \\
\text { - } \quad \text { Protection needs. }\end{array}$ \\
\hline $\begin{array}{l}\text { Theme 3: } \\
\text { The children expressed different meanings to their cultural identity. }\end{array}$ & $\begin{array}{l}\text { Cultural identity } \\
\text { - } \quad \text { Family background. } \\
\text { - } \quad \text { Language. } \\
\text { - } \quad \text { Religion. }\end{array}$ \\
\hline $\begin{array}{l}\text { Theme 4: } \\
\text { The children expressed uncertainty of the future as one of their experiences in } \\
\text { the residential care facilities. }\end{array}$ & $\begin{array}{l}\text { Preparation for leaving the care. } \\
\text { Previous negative experiences. }\end{array}$ \\
\hline
\end{tabular}

in a positive way. This is evident in the following statement: "I have a good relationship with my housemother; there is mutual respect and good communication. We get love from our housemother and we are regarded as a big happy family with the rest of my house brothers and sisters." The caregiver's relationship with the child is based on affection, mutual understanding and respect [14].

\section{Love, support and care}

Love, support and care were also identified as part of the positive relationship experience in terms of the care received from their housemothers. Various experiences of children in terms of love, support and care were expressed. One of the children stated the following: "My housemother is good and she gives me love. She is like my mother; there is no difference between her children and myself. All of us we are a family." It was proven that in some cases, well-functioning residential child care may offer better care than dysfunctional families [15]. Another child said that "Caring is about love. If someone cares about you at the same time he/she loves you. I like our home, our housemother cares about us.” According to Kendrick [16], "the quality relationship, characterised by care, love and support is intrinsic in children's definitions of 'family', and these can override structural relationships”. Another child expressed care in terms of support, by saying that:

"...Besides I have a good relationship with my housemother. She supports me in good and bad times. She gives me advice and I am happy to be here". It was stressed that children symbolise quality relationships in terms of care, love and support [12].

Child participation in everyday life decisions

Some children stated that active participation in everyday life decisions making contributed to the positive experience. Children revealed experiences in everyday life decisions making as a choice, obedience, permission, and consultation in a positive manner. One positive view on child participation in decision making is evident in the following statement: "I can make my own decision but also you have to consult our aunt. For instance, we have hours to watch TV and to do house chores during weekend. Like today is my day of cooking and I have decided to cook macaroni and meat." In support of the above-mentioned, child participation is defined as "children influencing issues affecting their lives, by speaking or taking action in partnership with adults” [17]. However, there were also some negative views on child participation in decision making on their everyday lives. Children experienced non-involvement in the decision making processes. This was revealed as a reflection of the instructions, directives, and strict rules in the facilities.

\subsubsection{Sub-Theme: Negative Relationship}

Negative relationship feelings identified by the child participants residing in RCCFs in terms of their care were, 
being uncomfortable, as well as loneliness and sadness. It is also normal for children in consultations to have different views and experiences about the same phenomena [18]. Below are some findings:

\section{Being uncomfortable}

Children complained about not being taken care of as expected. They felt that it was not comfortable to stay in the Residential Child Care Facilities, because they had to request permission to attend extramural activities, while they are part of their school activities. It was said that the housemothers do not care as they had their own children to take care of: "But other tannies don't take good care of other children, because they have their own children and husbands. Maybe it was going to be better if our housemothers are not married, maybe they were going to take a good care of us and pay more attention to us. [They take care of their husbands and kids.]". It is believed that the RCCFs have an important role to play in caring for the most difficult and demanding children and adolescents [19] who are reluctant to bond or trust anyone, especially adults [20]. Thus, "if such children are to be cared for safely and therapeutically, they need staff that are carefully selected and operating at high standards of professionalism" [19].

\section{Loneliness and sadness}

Children expressed that they were sad and lonely due to the fact that there were no family members around them. They did not value the care given by their housemothers: "I don't speak about my worries and concerns with my housemother. I keep them to myself, because she is not my mother. I don't have a family here, [I am sad and all alone]." According to [21], children who had trauma due to emotional and behavioural problems often find it difficult to cope with rules established in the RCCFs. Another theme identified during in-depth interviews with children was experience in relation with their basic needs:

\subsection{Theme 2: Participants Experienced Provision of Their Basic Needs as an Important Factor in the Caring Dimension}

Meeting the basic needs is indispensable for human survival and for people to be able to live decent lives [22]. Children's needs vary, but there are certain common and important ones that help them develop into independent adults and achieve their goals and independence.

\section{Sub-Theme: Provision of Basic Needs}

Children identified the basic needs as essential to their care. The findings of the provision of basic needs were identified as education, health, material (food, clothing \& shelter) and protection needs.

Educational needs

Children viewed education as one of the basic needs and valued the opportunity to finish their school while in RCCFs. The time they received to do their school work, without any disturbance, was not adequate. The school fees, transport and uniforms were provided to them as part of their education package: "It is good to be here, it is an opportunity to finish school, we get uniforms, the school fees are paid and we have a permanent transport that takes us to school, while other children from the locations have to walk to school." Children are placed in RCCFs because of various reasons; which may include gaining access to education, food and health care, which their biological families are not able to afford [23]. In addition, some parents believe that placing their children in residential care gives their children an opportunity for a better life in [23].

\section{Material needs (food, clothing and shelter)}

Participants revealed that they had never experienced food-related problems while in RCCFs: "The food we eat is well prepared and delicious. The food is always there and we eat three times a day." Other materials support such as clothing, toiletries and shelter were also expressed in a positive way: "You don't get everything you need, but at least you get the basics." If the basic needs of the child are not met, it will negatively affect other important aspects of the child's life [22].

\section{Health needs}

Children said they had access to clinics and hospitals if they fell sick while babies were also taken for immunization. They also said that each house had first aid kits in case of emergencies. The following are transcripts related to health needs from participants: "younger children are taken for immunization on a regular basis. If we are sick we are taken to Katutura hospital or nearby clinic." "If we are sick we are taken to the hospital and each house has a first kit". Reference [24] defines health as complete physical, mental and social well-being, rather than a mere absence of disease or infirmity. Thus, health is important in terms of care for children as health sets certain grounds for performance [22]. 


\section{Protection needs}

It is very important for children to live in a secure place. Participants interviewed expressed satisfaction in terms of protection. They spoke about being protected in the RCCFs, since they did not have parents to protect them: "[It's better to be here, because I don't have my biological mother to protect and to take care of me. At least here I am protected.]". It is the right of the child to be protected from all forms of abuse, neglect and exploitation whether under parental care, of a legal guardian or that of any other person entrusted with caring for the child [1].

Unfortunately, all children interviewed did not have the same experiences relating to their protection and safety. Some of the children claimed being abused by the caregivers who were supposed to be protecting them: The types of abuse experienced were described as verbal or emotional: "The uncle in our house is beating me up when he is drunk. Other 'tannies' also are not good and they beat you up sometimes. And also you are abused verbally or emotionally." Many children who live in RCCFs are among the most vulnerable in the world because they are at the highest risk of abuse and neglect due to poor standards of care in different residential care facilities [2].

The cultural identity theme was also identified as one of important aspects while caring children in Residential Child Care Facilities.

\subsection{Theme 3: The Children Expressed Different Meanings to Their Cultural Identity}

Preservation of identity is one of the children's rights and contact with the child's family members should be maintained [25]. Identity and social integration are based on a child's sense of belonging to a family and to the community. The below are sub-themes identified:

\section{Sub-Theme: Cultural Identity}

The sub-themes identified by the child participants residing in RCCFs were family background, language and religion.

\section{Family background}

According to the participants, being able to visit their biological parents and extended family members, as well as being with their siblings in the same RCCFs made them feel at home: "I am here with my two brothers and I feel good to be staying with them. We visit our parents during holidays, but we find it hard, it is not nice there because there is no food and it is very difficult for them to get food for us". This is important because, children need their families for emotional support as well as nurturing of their family bonds [22].

\section{Language}

In terms of language, children expressed different views. Some could speak their mother tongue, as they had kept contact with their families and others spoke Afrikaans and English which were being used in most facilities located in Windhoek. Some of the children showed no interest in learning their mother tongues: "I know my aunt; I visit her during long weekend and stay with them during holidays. I speak my mother tongue." Another view was expressed "So, my parents passed away and there is no one else who was willing to take care of me and my sister. Here we are and we are doing fine. We are supposed to be speaking Oshiwambo, but I don't know how to speak, here we speak English and Afrikaans." Although the children felt that they were not obliged to speak their mother tongue, it is the right of children to use their own language to be able to freely express themselves when communicating with those in their immediate family and in their community [1].

\section{Religion}

There were also different views on religious denominations. Some children attended their churches while others did not even know to which church they belonged. Although, the right of the children to follow their own religious and spiritual beliefs appears deceptively straightforward, despite its legal support, this right does not appear to be universally valued [26].

\subsection{Theme 4: Children Expressed Uncertainty of the Future as One of Their Experiences in Residential Child Care Facilities}

Children demonstrated uncertainty over their future because they did not know and did not have their care plans. Care plans determine why it is in the child's best interest to be looked after or whether other support services would be able to meet their needs. Care plans identify the assessed needs of the children and the services to meet 
those needs. The plans also set out the framework for the services provided to the child and family to enable the desired goals and outcomes in [27].

\subsubsection{Sub-Theme: Preparation for Leaving the Care}

Lack of proper preparation for leaving the care was given as one of the problems children faced in the RCCFs located in Windhoek. The preparation for leaving the care provided to them was more in relation to the use of the little financial assistance that they get. They used such money to buy their own food and toiletries monthly. Once they are outside of the facility, management of the facility build or rent rooms for them for a certain period or the children have a choice to be given a lump sum of money to take care of themselves: "I know that I will go out from this village soon. Currently, I am staying in the girls' hostel. We are being prepared to be able to take care of ourselves. They give every month an amount of money and you have to make sure that you buy food and toiletries that will last for month. It is not easy but we are managing. But when it is the time to go, they build a room outside the village and they give you money, until you are able to take care of yourself. If you have a family member who want to take you in it is also fine, they don't build a house for you, rather they give you a lump sum of money to take care of yourself."

However, most of the children interviewed were not prepared to go outside the facilities in the future. One participant expressed the fear in this way: "I know that I will not stay here forever. I want to be a mechanic so that I can take care of myself, since my father was not able to do so. But, I don't hear anything from the office about my future plan.” The transition from adolescence to adulthood is difficult. It is the time to make a decision about the future that entails education, career and living arrangements. This is the time when the family and friends are needed the most to help and guide the choices young people make. Unfortunately children in RCCFs are mostly forced to take such decisions on their own [28].

\subsubsection{Sub-Theme: Previous Negative Experience}

Previous negative experiences were expressed by participants as those who left the facilities not being able to cope in the real world on their own due to poor education which can lead to being jobless and homeless. It was an indication of lack of proper preparation for life outside care facilities: "I know that one day, I will leave this place. My parents passed away, I am staying here with my younger sister. My older sister used to stay here but she is out on her own. She doesn't have a place of her own she is sleeping with friends from one house to another and she has a baby. It is very not easy for her to survive." Children who grew up in RCCFs had a high probability of having lower educational attainment, high unemployment and low-level work status compared to all other children [29]. Care in RCCFs should be the utmost aspect, because the care children receive has a positive or negative impact on their survival, growth and development.

\section{Conclusions}

According to the discussions and findings from this study the following conclusions are made: It was revealed that the children's experiences of relationships were some of the factors contributing to their care. However, their views on such experiences differed from one child to another, either positively or negatively. Those who experienced positive relationships described it as being manifested through love, support and care; mutual understanding and good communication. Negative relationships were viewed as being uncomfortable, lonely and sad. Thus, relationships between the children and housemothers and other staff members in RCCFs contributed to the caring aspects. They promoted the well-being of children in different aspects that affected their lives.

The provision of basic needs was also a pillar in their care. Those basic needs were acknowledged as education, material support (food, clothing and shelter), health and protection. Basic needs are essential for human survival [22] and one of the reasons for children being placed in residential care is for them to get access to food, education, health care that their biological families are not able to provide [23]. All children interviewed had access to education. They attended different government and private schools located in Windhoek. Most of the children admitted that they were not performing well in their school work, but still they had various positive ambitions and dreams for their future. It was also noted that although they were given enough time and reminded of their school and homework, they had limited support from their housemothers on them.

Cultural identity is also one of the components of care. Preservation of identity which is one of the child's rights and contact with family members should be encouraged and maintained [25]. The sub-components identi- 
fied were family background—children needed to know their origin. The children knew their place of birth, with an exception of one child. Children with parents visited their families during holidays and those without families visited a family friend during holidays too. On the other hand, there were few cases where children did not want to have any contact with their biological parents.

Language and religion were identified as some of the sub-components of failure to achieve cultural identity. In all the three RCCFs, the medium of communication was Afrikaans and children did not have an opportunity to speak their mother tongues. Religion was considered to be the last need for the children as they were not given any opportunity to practice their faiths. Therefore, children should be encouraged to speak their mother tongue or local language so that they develop a positive self-image. A sense of belonging and identity should be seen as a central part of the care services that should be provided to children in residential care facilities. Children in RCCFs should continue to have regular contact with their biological families or extended families where applicable and such contact with the family of origin should be seen as important to child development and well-being and a step further to successful reintegration of children into their communities.

Uncertainty of the future was also a negative issue identified by children. There is no much being done in terms of preparing children outside life once they leave RCCFs. At the same time, the children who were interviewed did not know what would happen to them once they left the facilities. Bad experiences also from previous children who lived in RCCFs were counted and after leaving the facilities they did not have decent lives. Examples of some children on the street, others who feel pregnant and unemployment after care were narrated.

\section{Recommendations}

The following recommendations were made based on the results of the study:

Education needs: All children in Namibia have the right to have an education; therefore, it is recommended that measures to improve the quality of education for children in RCCFs should be put in place. The Ministry of Gender Equality and Child Welfare and other stakeholders need to work together to ensure that poor children including those in RCCFs access financial support and other forms of support that will enable them to access better education at all levels, since education can influence the quality of life in various ways [22] Thus, in RCCFs, support for education should be comprised of not only paying school fees, providing uniforms and transport, but supporting children in their homework and ensuring regular contact and consultations with class teachers to monitor the progress of the child in terms of school work and discipline.

Child participation in everyday life decisions: Reference [1] emphasises child participation in terms of expressing their views in matters affecting their everyday lives. Children in RCCFs should be a part of the processes of formulating rules and regulations including subsequent amendment to ensure clear understanding about the purpose of the rules and regulations established among children concerned.

Children participation in every day decisions concerning the care they receive while in placement should be seen as crucial, not only to safeguard and guarantee their rights, but to enable them to participate in decisions that affect them. Active participation can be an effective way of teaching them life skills. Learning to consider options and to participate in decisions is an important aspect to their development towards becoming responsible, independent and resourceful citizens.

Involving children in developing and maintaining the rules and regulations of the RCCFs should incorporate the creation of suggestion boxes to gather children's views which are regularly reviewed and responded to. There is a need to support the establishment of children's groups in which children have their own regular space to raise and discuss issues affecting them. Family talk events where all staff members and children come together are good examples.

Children should be allowed to have their own regular meetings without staff members present for them to raise problems concerning their care and share their viewpoints without fear. This can enable them to develop strategies on how they convey their message to the management of the facilities. In some instances, it would be good to have an external facilitator to ensure that children's issues in care facilities are brought to the attention of the managers of those facilities as a part of advocacy. In turn, the managers should be able to address problems brought to their attention fairly.

Protection needs: A child protection policy and prevention that includes reporting systems should be developed for RCCFs including clear accountability for violations. In addition, a support system should be in place for the children to report cases of abuse safely and confidentially. The support systems should preferably be lo- 
cated at the Ministry of Gender Equality and Child Welfare.

A mechanism for receiving and considering complaints by children who are in the facilities in a way that ensures children's safety at all times should be put in place by the Ministry of Gender Equality and Child Welfare where such facilities are located.

Cultural identity: Children should be encouraged to speak their mother tongue or local language so that they develop a positive self-image. A sense of belonging and identity should be seen as a central part of the care services that should be provided to children in residential care facilities. They should continue to have regular contact with their biological families or extended families where applicable and such contact with the family of origin should be seen as important to child development and well-being and a step further to successful reintegration of children into their communities. Residential Child Care Facilities should be able to work with the families and communities where children come from in order to strengthen the family relationships rather than working in isolation.

Preparation for leaving the care: The Ministry of Gender Equality and Child Welfare should ensure that children do not stay in RCCFs without adequate individual and family status assessments and a child's care plan. Residential Child Care Facilities should work towards re-integrating the child into the family of origin if it exists or other identified close extended family members. Children should not stay in care facilities until they are old enough to leave without a clear plan to continue living in safety, as they will find it difficult to re-join mainstream society [30].

Preparation for leaving care should not just be a care for "after finishing school”, but consideration should be taken in terms of managing the separation of the children with house mothers with whom they would possibly formed deep attachments with. Leaving the facility should be supported as a critical step in the child's development and children should be helped to see it as a part of their preparation for life ahead. Thus, strategies of care leaving for each child should be developed and reviewed as part of the care plan throughout the placement, from school to higher education or work, as well the transition to the new social life. The aim of placement should be to support children to move towards a better and more secure life within their communities.

\section{Acknowledgements}

Sincere gratitude is conveyed to the management of the three RCCFs and children who participated in this study of the three RCCFs. Without your willingness to participate, this would have been unachievable.

\section{References}

[1] United Nations Convention on the Rights of the Child (1989) UNICEF, Geneva.

[2] Save the Children (2012) Guidelines for the Alternative Care of Children. http://resourcecentre.savethechildren.se/node/6892

[3] Browne, K. (2009) The Risk of Harm to Young Children in Institutional Care. The Save Children Fund, London

[4] Ministry of Health and Social Services. Demographic Health Survey 2006/2007.Windhoek: Namibia.

[5] UNICEF (2006) Alternative Care for Children without Primary Caregivers in Tsunami-Affected Countries, Indonesia, Malysia, Mynmar and Thailand. UNICEF East Asia AND Pacific Regional Office, Bangkok.

[6] Van Der Walt, C. and Van Rensburg, G. (2006) Fundamentals of Research Methodology for Health Care Professionals. 2nd Edition, Juta \& Co. (Pty) Ltd., Cape Town.

[7] Polkinghorne, D.E. (2005) Language and Meaning: Data Collection in Qualitative Research. Journal of Counselling Psychology, 52, 137-145.

[8] Tesch, R. (1990) Qualitative Research: Analysis Types and Software Tools. The Falmer Press, New York.

[9] Al-Busaidi, Z. (2008) Qualitative Research and Its Uses in Health Care. Sultan Qaboos University Medical Journal, 8, 11-19.

[10] Punch, K. (2005) Introduction to Social Research: Quantitative and Qualitative Approaches. 2nd Edition, Sage, London.

[11] Pia, C. and Allison, J. (2008) Research with Children: Perspectives and Practices. 2nd Edition, Routledge, New York.

[12] Kendrick, A. (2012) What Research Tells Us about Residential Child Care? Palgrave Macmillan, Basingstoke.

[13] McDonald, G. and Millen, S. (2012) Implementing Therapeutic Approaches to Residential Child Care in Northern Ire- 
land: Report of Interviews with Trust Staff. Social Care Institute for Excellence, London.

[14] Oates, J. (2007) Attachment Relationships: Quality of Care for Young Children. Open University, Milton Keynes.

[15] Jelsma, J.M., Davids, N. and Furguson, G. (2011) The Motor Development of Orphaned Children with and without HIV/AIDS: Pilot Exploration of Foster Care and Residential Placement. BMC Paediatrics, 11, 1471-2431. http://dx.doi.org/10.1186/1471-2431-11-11

[16] Kendrick, A. (2013) Relationships and Relatedness: Residential Child Care and the Family Metaphor. Child and Family Social Work, 18, 77-86. http://dx.doi.org/10.1111/cfs.12040

[17] Stephenson, P., Gourley, S. and Miles, G. (2004) Child Participation. Tearfund, London.

[18] Morgan, R. (2009) Care and Prejudice. A Report of Children's Experience by the Children's Rights Director for England. Ofsted, Manchester.

[19] Stevens, I. and Furnivall, J. (2008) Therapeutic Approaches in Residential Care. In: Kendrick, A., Ed., Residential Child Care: Prospects and Challenges, Jessica Kingsley Publishers, London.

[20] Mikulincer, M. and Shaver, P.R. (2007) Attachment in Adulthood: Structure, Dynamics, and Change. Guilford Publications, Inc., New York.

[21] Byrne, J. (2005) Social Care Workers’ and Students’ Perspectives on Issues Related to Professional Status and Representation of Social Care in Ireland. Waterford Institute of Technology, Waterford.

[22] Kristiansen, M. (2009) The Quality of Life of Children living in Residential Child Care Facilities: A Comparative Study of Three Children's Homes in Accra and Cape Coast, Ghana. Norwegian University of Science and Technology, Trondheim.

[23] Every Child (2009) Missing: Children without Parental Care in International Development Policy. Every Child, London.

[24] WHO (2006) Constitution of the World Health Organization: Basic Documents. http://www.who.int/governance/eb/who_constitution_en.pdf

[25] Martin, F. and Sudrajat, T. (2007) Someone That Matters: The Quality Care in Child Care Institutions in Indonesia. Save the Children UK, Jakarta.

[26] Barratt, C. (2009) Supporting the Religious and Spiritual Needs of Looked-After Children and Accommodated in Scotland. Scotland Journal of Residential Child Care, 8, 39-51.

[27] Kane, S. (2007) Care Planning for Children in Residential Care. National Children's Bureau, London.

[28] Kilkenny, M.T. (2012) The Transition to Adulthood and Independence: A Study of Young People Leaving Residential Care. School of Social Sciences and Law/Dublin Institute of Technology, Dublin.

[29] Bilson, A. and Cox, P. (2007). Caring Poverty: Alternatives to Institutional Care for Children in Poverty. Journal of Children and Poverty, 13, 37-55. http://dx.doi.org/10.1080/10796120601171294

[30] Williamson, J. (2004) A Family Is for a Life Time. TvT Global Health and Development Strategies, TM a Division of Social \& Scientific Systems, Inc., Washington DC. 